\title{
Optimization of xylanase production by Streptomyces sp. P12-137 using response surface methodology and central composite design
}

\author{
Gigi Coman • Gabriela Bahrim
}

Received: 15 September 2010 / Accepted: 30 December 2010/Published online: 8 February 2011

(C) The Author(s) 2011. This article is published with open access at Springerlink.com

\begin{abstract}
Response surface methodology and central composite design were used to optimize a biosynthesis medium for the production of xylanases by Streptomyces sp. P12-137 in submerged fermentation culture at $\mathrm{pH} 5.0$, with wheat bran as substrate. The three variables involved in this research were the wheat bran, potassium nitrate and xylose concentrations. Statistical analysis of the results showed that, in the range studied, xylose and potassium nitrate concentrations had a significant effect on xylanase production. The optimized biosynthesis medium contained (in \%,w $/ \mathrm{v}$ ): wheat bran $1.0, \mathrm{KNO}_{3} 1.0$, xylose 0.5 . This medium resulted in a 3 -fold increased level of the xylanase $(27.77 \mathrm{UA} / \mathrm{ml})$ production compared to the initial level $(8.30 \mathrm{UA} / \mathrm{ml})$ after $120 \mathrm{~h}$ of fermentation, whereas the value predicted by the quadratic model was $26.45 \mathrm{UA} / \mathrm{ml}$.
\end{abstract}

Keyword Xylanase $\cdot$ Streptomyces $\cdot$ Response surface methodology Optimization · Central composite design

\section{Introduction}

Lignocellulose biomass represents an unexploited resource. There is increasing interest in using hemicelluloses wastes for bioconversion, with a view to obtaining unconventional energy and food resources (Rosado and Nadathur 2003; Coman et al. 2008).

G. Coman $(\bowtie) \cdot$ G. Bahrim

Faculty of Food Science and Engineering,

Bioengineering in Food Industry Department,

"Dunărea de Jos" University,

111 Domnească Street,

800201 Galați, Romania

e-mail: gicoman@ugal.ro
Xylan is a major component of plant cell walls, which constitute approximately one-third of all renewable organic carbon sources on Earth. Complete xylan degradation requires the combined action of different xylanolitic enzymes, such as endo-xylanase, $\beta$-xylosidase, $\alpha$-arabinofuranosidase, and esterase (Techapun et al. 2002a, b). Xylanase (1,4- $\beta$-D-xylan xylanohydrolase, EC 3.2.1.8) is an important component in a group of enzymes that act by depolymerizing the xylan molecules into monomers that can be used by microbial systems as a primary source of sugar (Goulart and Carmona 2005). The products of xylan hydrolysis are xylose, xylobiose, xylotriose, xylotetrose and xylo-oligosaccharides. These compounds have possible applications as food additives for poultry, in wheat flour for improving dough handing and the quality of baked products, for extraction of coffee and plant oils, and in combination with pectinase and cellulase for the clarification of fruit juices and wines (Ninave et al. 2008). Xylanase has been used in bleaching during paper production, resulting in reduced use of chemicals. The alkali-stable xylanase can reduce pollution due to chloro-organo compounds in the paper pulp industry by avoiding the need for the use of chlorine which is also a significant health hazard, for bleaching (Senthilkumar et al. 2005; Buchert et al. 1994).

Culture medium optimization by the traditional "onefactor-at-a-time" technique requires a considerable amount of time and work. An alternative, statistical strategy is to use factorial experimental design and response surface methodology (RSM), which involves a minimum number of experiments and covers a large number of factors. These methods have also been employed to improve the production of microbial xylanases in submerged culture.

RSM is a popular optimization method used in recent years. There are many reports of studies based on the application of RSM in biochemical and biotechnological processes (Bas and 
Boyaci 2007). RSM comprises statistically designed experimental techniques for estimating the coefficients in a mathematical model and predicting the response and checking the applicability of the model (Techapun et al. 2002a, b).

Central composite design (CCD) contains a factorial matrix with center points and "star points" around that center point that allow the curvature of the model to be established. The distance from the center of the design space to a factorial point is \pm 1 unit for each factor, and the distance space from the center of the design space to a star point is $\pm \alpha$, where $|\alpha|>1$. The precise value of $\alpha$ depends on the number of factors used. The star point represents extreme values for each factor in the design.

The present work describes the successful optimization of a culture medium for the production of the xylanase by Streptomyces sp. P12-137 in submerged fermentation (SmF).

\section{Materials and methods}

\section{Microorganism}

Streptomyces sp. P12-137 was used in this study. This strain was isolated from a soil sample obtained from the Galați region and selected as a potent producer of xylanase. This strain was propagated on Gauze-agar medium at $28^{\circ} \mathrm{C}$ and maintained at $4^{\circ} \mathrm{C}$. After growth for $72 \mathrm{~h}$, spores and aerial mycelium were harvested in $10 \mathrm{ml}$ sterile $\mathrm{NaCl}(0.9 \%)$ to be used as inoculum.

\section{Production of xylanase}

The unoptimized fermentation medium is composed of $(\mathrm{g} / \mathrm{l})$ : birchwood xylan $10 \mathrm{~g}, \mathrm{~K}_{2} \mathrm{HPO}_{4} 0.075 \mathrm{~g}, \mathrm{KH}_{2} \mathrm{PO}_{4} 1.5 \mathrm{~g}$, $\mathrm{KNO}_{3} 4.5 \mathrm{~g}$, and a trace element solution $2.7 \mathrm{ml} / 1$ that comprised (g/l): $\mathrm{ZnSO}_{4} \cdot 7 \mathrm{H}_{2} \mathrm{O} 0.14 \mathrm{~g}, \mathrm{MnSO}_{4} \cdot \mathrm{H}_{2} \mathrm{O} 0.16 \mathrm{~g}$, $\mathrm{FeSO}_{4} \cdot 7 \mathrm{H}_{2} \mathrm{O} 0.5 \mathrm{~g}, \mathrm{CoCl}_{2} \cdot 2 \mathrm{H}_{2} \mathrm{O} 0.2 \mathrm{~g}$ in distilled water. The $\mathrm{pH}$ of the medium was adjusted to 7.2 after sterilization using sterile $1 \mathrm{~N} \mathrm{NaOH}$. Erlenmeyer flasks $(250 \mathrm{ml})$ containing $50 \mathrm{ml}$ sterile culture medium were inoculated with $2.5 \mathrm{ml}$ inoculum. The flasks were incubated at $28^{\circ} \mathrm{C}$ for $120 \mathrm{~h}$ on an orbital shaker. The extract was centrifuged at $10,000 \mathrm{~g}$ and at $4^{\circ} \mathrm{C}$ for $10 \mathrm{~min}$, and the clear supernatant was assayed for xylanase activity. For optimization studies, the composition of the culture medium was varied according to the experimental data, while the $\mathrm{pH}$, temperature and time of fermentation were not varied.

\section{Xylanase assay}

Xylanase activity was determined using birchwood xylan (Roth, Karlsruhe, Germany) (Bailey et al. 1992). A $0.2 \mathrm{ml}$ culture supernatant was added to $2 \mathrm{ml}$ xylan solution $(1.5 \%$;
$\mathrm{pH} 5.0 ; 200 \mathrm{mM}$ acetate buffer) and incubated at $50^{\circ} \mathrm{C}$. After $20 \mathrm{~min}, 2 \mathrm{ml} \mathrm{3,5-dinitrosalicylic} \mathrm{acid} \mathrm{reagent} \mathrm{was} \mathrm{added} \mathrm{to}$ stop the reaction, and the amount of reducing sugars released in the reaction was estimated by measuring the absorbance at $535 \mathrm{~nm}$ (Miller 1959). One unit (1 UA) of xylanase activity is defined as the amount of enzyme required to release $1 \mu \mathrm{mol}$ xylose per minute under the assay conditions.

\section{Response surface methodology}

A factorial CCD for three factors with replicates at the center point and star point was used in this investigation. The variables used were wheat bran, $\mathrm{KNO}_{3}$ and xylose each at five coded levels $(-\alpha,-1,0,+1,+\alpha)$, as shown in Table 1 .

The relation between the coded forms of the input variable and the actual value of the wheat bran, $\mathrm{KNO}_{3}$ and xylose are described in Eq. 1:

$X_{i}=\frac{\left(Z_{i}-Z_{0}\right)}{\Delta Z}$

where $X_{\mathrm{i}}$ is a coded value and $Z_{\mathrm{i}}$ the actual value of the factor, $Z_{0}$ the actual value of the same variable at the center point, $\Delta Z$ the step change of the variable. The CCD contained a total 15 experimental trials that included four trials for factorial design, six trials for axial points (two for each variable), and five trials for the replication of the central points (see Table 2).

These three factors, each with five coded levels consisting of 15 experimental runs, were used to analyze the experimental data to allow for a better estimate of the experimental error and to provide an extra information region (Haaland 1990). The experimental data were fitted according to Eq. 2 as a second-order polynomial regression equation, including individual and cross effect of each variable.

$Y=b_{0}+\sum_{i=1}^{3} b_{i} X_{i}+\sum_{i=1}^{3} b_{i i} X_{i}^{2}+\sum_{i=1}^{2} \sum_{j=i+1}^{3} b_{i j} X_{i} X_{j}$

where $Y$ is the predicted response, $b_{0}$ is the intercept term, $b_{\mathrm{i}}$ is the linear effect, $b_{\mathrm{ii}}$ is the square effect, $b_{\mathrm{ij}}$ is the interaction effect, and $X_{\mathrm{i}}$ and $X_{\mathrm{j}}$ are the variables. Equation 2 was used to optimize the values of independent parameters for the response.

Table 1 Variables and their levels for the experimental central composite design (CCD)

\begin{tabular}{llllll}
\hline Variable & \multicolumn{5}{l}{ Coded level of variable } \\
\cline { 2 - 6 } & $-\alpha$ & -1 & 0 & +1 & $+\alpha$ \\
\hline Wheat bran $(\%, \mathrm{w} / \mathrm{v})$ & 0.80 & 1.00 & 1.50 & 2.00 & 2.20 \\
$\mathrm{KNO}_{3}(\%, \mathrm{w} / \mathrm{v})$ & 0.04 & 0.20 & 0.60 & 1.00 & 1.16 \\
Xylose $(\%, \mathrm{w} / \mathrm{v})$ & 0.02 & 0.10 & 0.30 & 0.50 & 0.78 \\
\hline
\end{tabular}


Table 2 Experimental design and results of CCD

\begin{tabular}{lllllll}
\hline Run & \multicolumn{2}{l}{ Coded levels } & & & Responses \\
\cline { 2 - 3 } \cline { 5 - 6 } & A & B & C & & $\begin{array}{l}\text { Actual value } \\
(\mathrm{UA} / \mathrm{ml})\end{array}$ & $\begin{array}{l}\text { Predicted value } \\
(\mathrm{UA} / \mathrm{ml})\end{array}$ \\
\hline 1 & 0 & 0 & 0 & 6.23 & 8.02 \\
2 & 1 & 1 & -1 & & 2.52 & 1.2 \\
3 & 1.41 & 0 & 0 & & 9.98 & 11.3 \\
4 & $-1,41$ & 0 & 0 & & 10.69 & 9.37 \\
5 & 0 & $-1,41$ & 0 & & 15.99 & 17.31 \\
6 & 0 & 0 & 0 & & 9.17 & 8.02 \\
7 & 1 & -1 & 1 & & 13.4 & 12.08 \\
8 & 0 & 0 & 0 & & 12.27 & 8.02 \\
9 & -1 & 1 & 1 & & 27.77 & 26.45 \\
10 & 0 & 0 & $-1,41$ & 4.8 & 6.12 \\
11 & -1 & -1 & -1 & & 10.69 & 9.37 \\
12 & 0 & 0 & 0 & & 5.88 & 8.02 \\
13 & 0 & 1,41 & 0 & 9.23 & 10.55 \\
14 & 0 & 0 & 1,41 & 6.51 & 7.83 \\
15 & 0 & 0 & 0 & 9.22 & 8.02 \\
\hline
\end{tabular}

Statistical analysis

The statistical software package Design-Expert (Stat-Ease, Minneapolis, MN) was used for a regression analysis of experimental data and to plot the response surface. Variance analysis (ANOVA) was used to estimate the statistical parameters.

\section{Results and discussion}

The results of experimental xylanase production by a complete three factor and two level factorial experiment design with five replications of the central point and six axial points are show in Table 2. The interaction term $A B$

Table 3 Regression analysis of CCD

\begin{tabular}{llll}
\hline Source & Mean square & F-value & Prob $>$ F \\
\hline Model & 50.03 & 5.43 & 0.0385 \\
A-wheat bran & 0.25 & 0.027 & 0.8749 \\
B-KNO $_{3}$ & 22.85 & 2.48 & 0.1762 \\
C-xylose & 1.46 & 0.16 & 0.7068 \\
$\mathrm{AB}$ & 81.53 & 8.85 & 0.031 \\
$\mathrm{AC}$ & 31.05 & 3.37 & 0.1259 \\
$\mathrm{BC}$ & 57.96 & 6.29 & 0.054 \\
$\mathrm{~A}^{2}$ & 25.46 & 2.76 & 0.1574 \\
$\mathrm{~B}^{2}$ & 67.33 & 7.31 & 0.0426 \\
$\mathrm{C}^{2}$ & 2.11 & 0.23 & 0.6522 \\
Lack-of-fit & 18.89 & 2.78 & 0.1708 \\
\hline
\end{tabular}

(wheat bran and $\left.\mathrm{KNO}_{3}\right)(P<0.05)$ and $\mathrm{B}^{2}$ term $(P<0.05)$ were statistically significant (Table 3 ).

The parameters of Eq. 1 were determined by multiple regression analysis by application of the RSM method. The second-order polynomial regression equation showing the relationship between the xylanase activity $(Y)$ and three test variables in coded units is represented in Eq. 3:

$$
\begin{aligned}
\mathrm{Y}= & 8.67 B+29.61 C-31.93 A B-39.40 A C+67.29 B C \\
& +7.26 A^{2}+18.47 B^{2}-13.09 C^{2}-1.07
\end{aligned}
$$
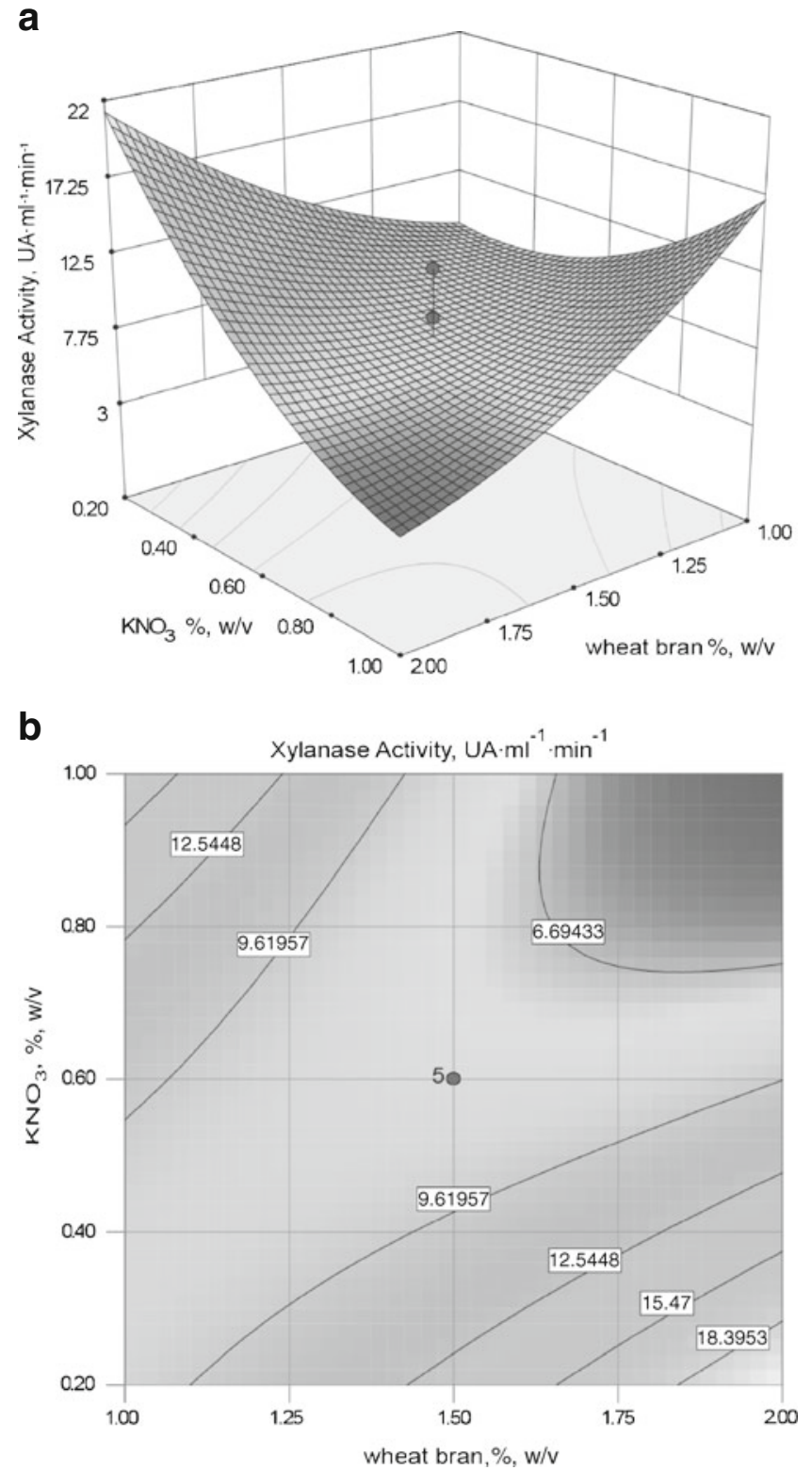

Fig. 1 Response surface curves (a) and contour plots (b) of xylanase production from Streptomyces sp. P12-137, showing interactions between wheat bran and $\mathrm{KNO}_{3}$ concentrations after $120 \mathrm{~h}$ of incubation 


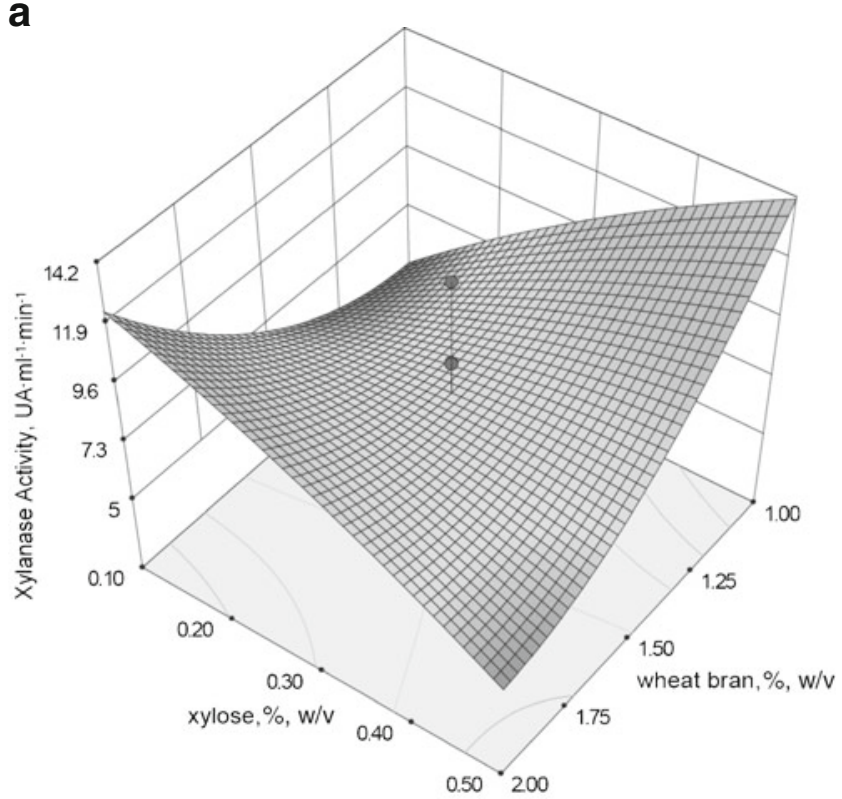

b

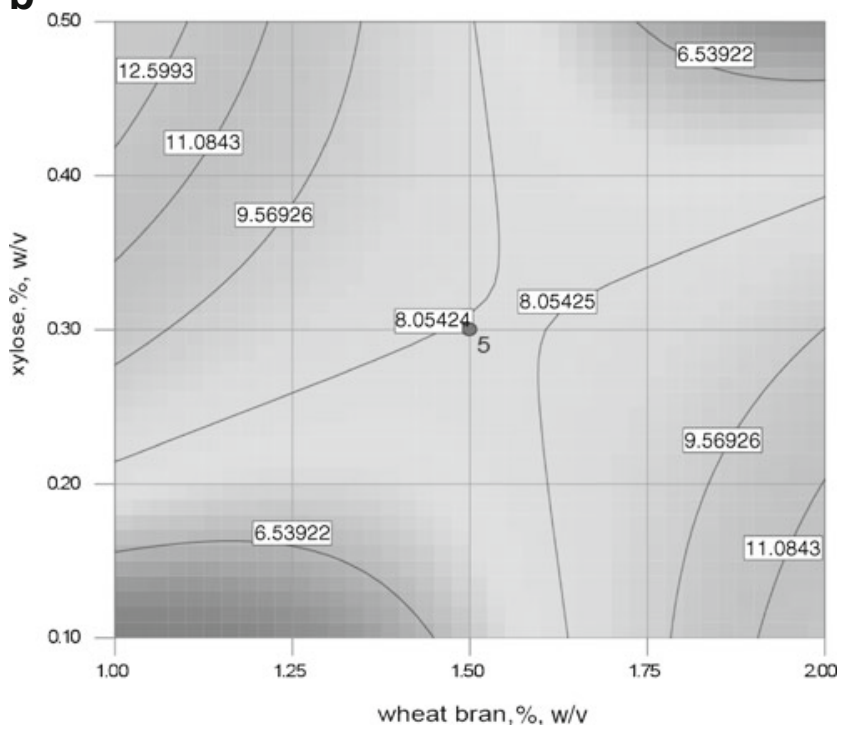

Fig. 2 Response surface curves (a) and contour plots (b) of xylanase production from Streptomyces sp. P12-137 showing interactions between wheat bran and xylose after $120 \mathrm{~h}$ of incubation

where $Y$ is the xylanase activity ( $\mathrm{UA} / \mathrm{ml}), \mathrm{A}$ is the wheat bran $(\mathrm{g} / \mathrm{l}), \mathrm{B}$ is $\mathrm{KNO}_{3}(\mathrm{~g} / \mathrm{l})$ and $\mathrm{C}$ is the xylose $(\mathrm{g} / \mathrm{l})$. The statistical significance of the model equation was evaluated by the Ftest for ANOVA, which showed that the regression is statistically significant at the $0.90(P<0.05)$ confidence level.

A value of $P>\mathrm{F}$ less than 0.05 indicates that the model terms are also significant. The coefficient of determination $\left(R^{2}\right)$ was calculated to be 0.9072 , indicating that the model could explain $90 \%$ of the variability. The "lack-of-fit F-value" of 2.78 implies that the lack of fit is significant. There is only a $0.01 \%$ chance that a "lack-of-fit F-value" this large could occur due to noise. The estimated models fit the experimental data adequately. "Adeq Precision" is a statistical parameter that measures the signal (response) to noise (deviation) ratio. The observed ratio of 10.187 indicates an adequate signal and therefore the model is significant for the process. Threedimensional (3D) response surfaces were plotted on the basis of the model equation in order to investigate the interaction among the variables and to determine the optimum concentration of each factor for maximum xylanase production by Streptomyces sp. P12-137. Figure 1 shows the interactions with wheat bran as carbon source and $\mathrm{KNO}_{3}$ as nitrogen source. Xylanase production increases with increasing wheat bran concentration $(1 \%, \mathrm{w} / \mathrm{v}$ to $2 \%, \mathrm{w} / \mathrm{v})$ and $\mathrm{KNO}_{3}$ $(0.20 \%, w / v$ to $1 \%, w / v)$.
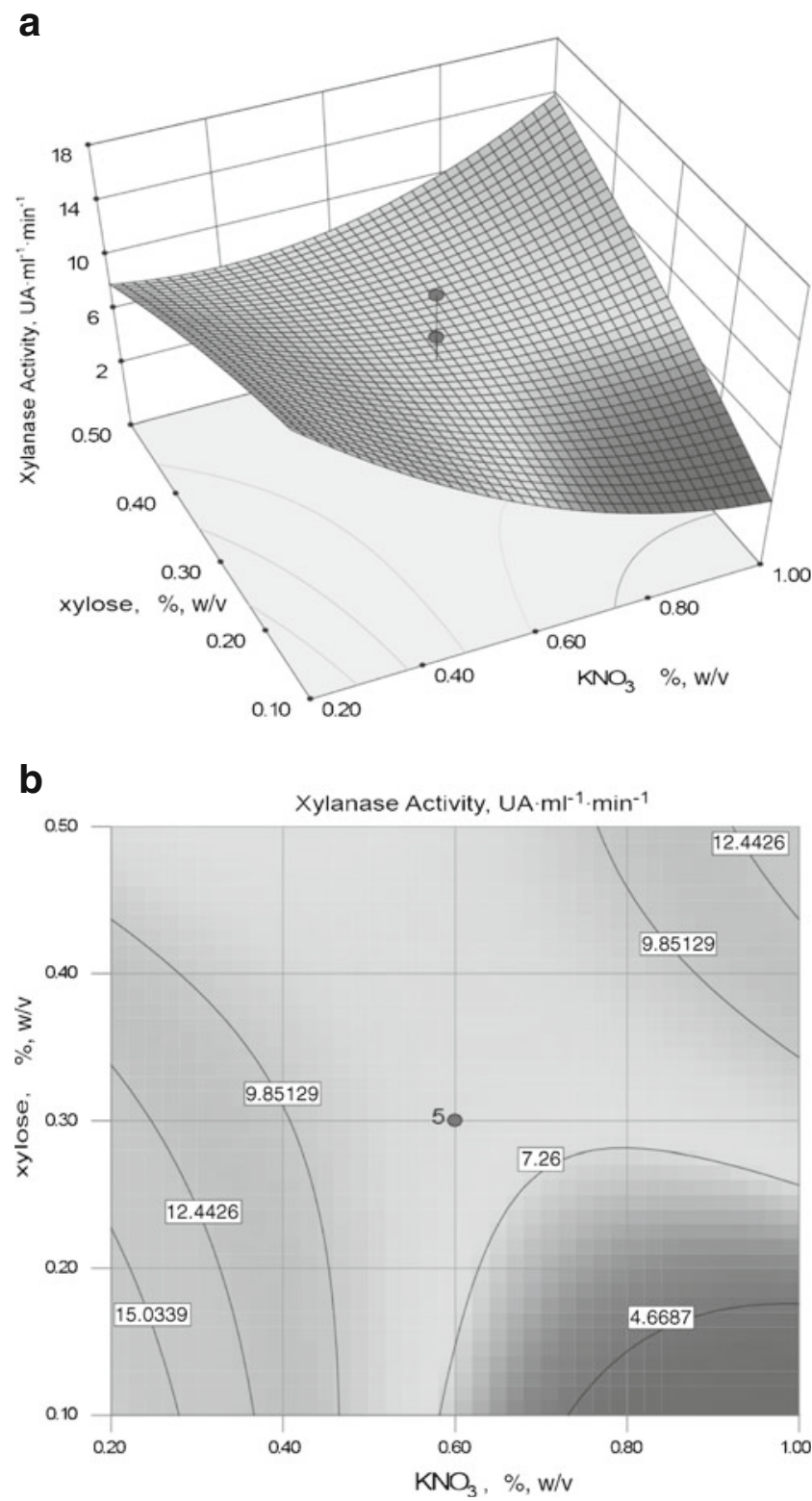

Fig. 3 Response surface curves (a) and contour plots (b) of xylanase production from Streptomyces sp. P12-137 showing interactions between xylose and $\mathrm{KNO}_{3}$ after $120 \mathrm{~h}$ of incubation 


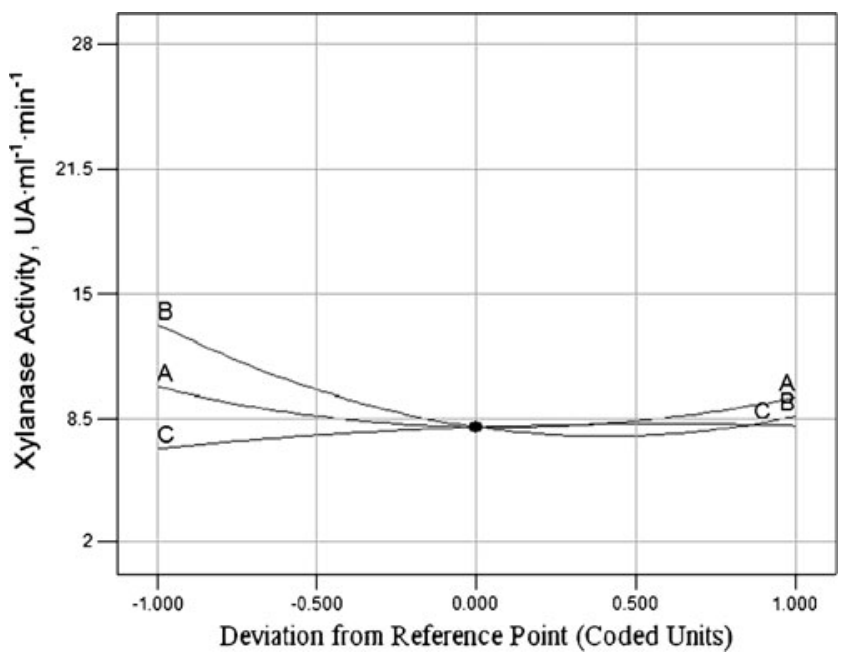

Fig. 4 Perturbation graph for three factors involved in xylanase production: $A$ wheat bran, $B \mathrm{KNO}_{3}, C$ xylose

The effects on xylanase production of changes in the concentration of wheat bran and xylose are shown in Fig. 2. Xylanase production increases with simultaneous increases in the concentrations of wheat bran and xylose from $1.5 \%$, $\mathrm{w} / \mathrm{v}$ to $2 \%, \mathrm{w} / \mathrm{v}$ and $0.20 \%$, w $/ \mathrm{v}$ to $0.5 \%$, w/v, respectively. A decrease in xylanase activity was observed at $1.5 \%, \mathrm{w} / \mathrm{v}$ wheat bran concentration and $0.30 \%$, w $/ \mathrm{v}$ xylose in the gutter area of the response. Low xylanase productivity was recorded when the concentration of wheat bran and xylose was less than $1 \%, \mathrm{w} / \mathrm{v}$ and $0.10 \%$, w/v or increased more than $2 \%, \mathrm{w} / \mathrm{v}$ and $0.5 \%$, w/v, respectively.

The effects on the production of xylanase of variation in the concentration of $\mathrm{KNO}_{3}$ and xylose, with the wheat bran concentration kept constant, are shown in Fig. 3. Increased

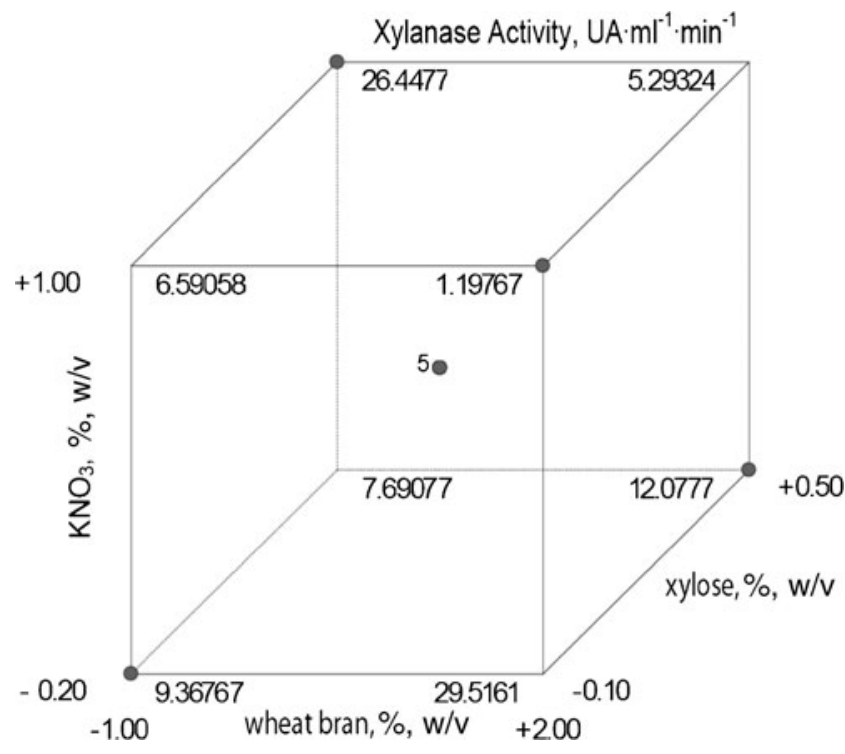

Fig. 5 Cube plot showing the influence of factors relevant to xylanase production: $A$ wheat bran, $B \mathrm{KNO}_{3}, C$ xylose

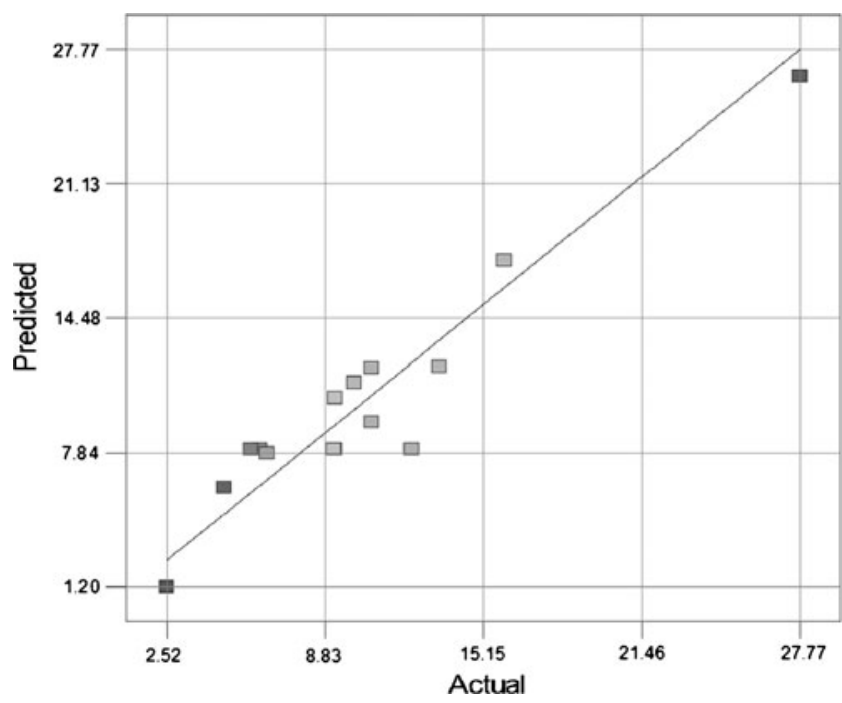

Fig. 6 Parity plot showing the distribution of experimental vs predicted values of xylanase production

xylanase activity recorded at low levels of $\mathrm{KNO}_{3}$ and xylose of $0.20 \%, \mathrm{w} / \mathrm{v}$ and $0.10 \%$, w/v, respectively, but not at high concentrations of $\mathrm{KNO}_{3}$ (over $1 \%$, w/v) and xylose concentrations of $0.50 \%, \mathrm{w} / \mathrm{v}$. Any increase of xylose concentration over $0.50 \%, \mathrm{w} / \mathrm{v}$ has a repressive catabolic action on xylanase production.

Also, a steep reduction in xylanase production was recorded at low levels of xylose $\left(<0.10 \%\right.$, w/v) and $\mathrm{KNO}_{3}$ increases over $1 \%, \mathrm{w} / \mathrm{v}$. Thus, it can be concluded that the enzyme production is stimulated at relatively low concentrations of xylose and nitrogen, or with higher amounts of nitrogen source when xylose does not exceed $0.50 \%$, w/v.

Perturbation graphs help compare the effect for every factor on a particular point using space design. The response is

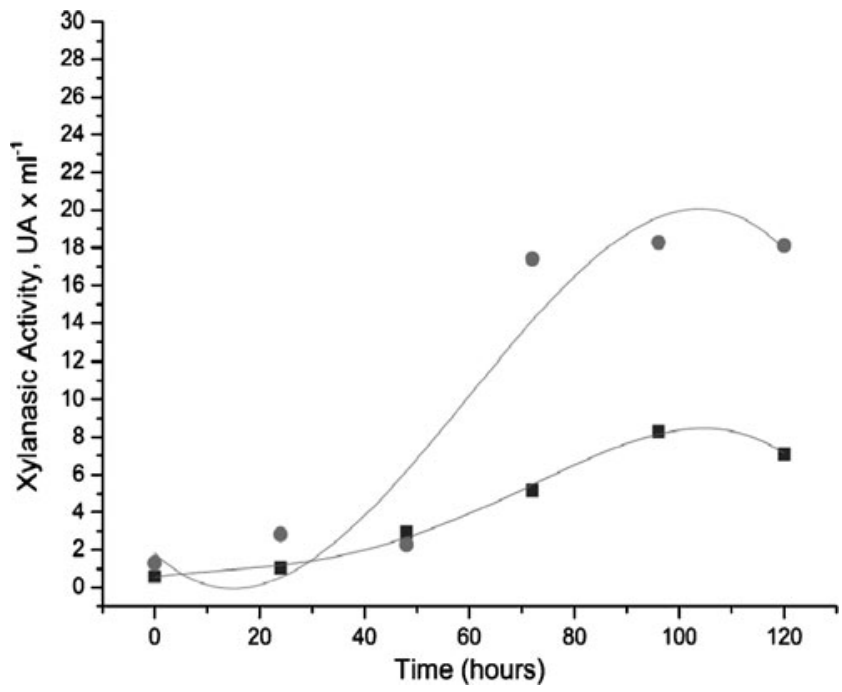

Fig. 7 Dynamics of xylanase production by Streptomyces sp. P12-137 in submerged fermentation $(\mathrm{SmF})$ with the medium before ( $\boldsymbol{(})$ and after optimization $(\bullet)$. Each value is the mean value of $n=3$ experiments 
shown graphically by changing one factor while other factors remain constant. One factor that was found to affect xylanase biosynthesis by streptomycetes is the source of nitrogen (Fig. 4, curve b) followed by carbon source (curve a).

The cube plot (Fig. 5) shows the maximum xylanase activity at a point $(\mathrm{A}+\mathrm{B}-\mathrm{C})$ located in the bottom right, where a response of value $29.5161 \mathrm{UA} / \mathrm{ml}$ was predicted, corresponding to increasing levels of wheat bran $(2 \%, w / v)$ and $\mathrm{KNO}_{3}(1 \%, \mathrm{w} / \mathrm{v})$ and a low concentration of xylose $(0.10 \%, \mathrm{w} / \mathrm{v})$. This chart confirms the repressive action of high levels of xylose in the culture medium. The central point represents the optimal point of the combined action for the three factors, at values of $1.5 \%, \mathrm{w} / \mathrm{v}$ for wheat bran, $0.6 \%, \mathrm{w} / \mathrm{v}$ for $\mathrm{KNO}_{3}$ and $0.3 \%$, w/v for xylose.

The parity plot showed a satisfactory correlation between experimental values and predicted values (Fig. 6), wherein the points cluster around the diagonal, which indicates the good fit of the model, since the deviation between the experimental and predicted values was small.

Design-Expert predicted the maximum xylanase yield to be $26.45 \mathrm{UA} / \mathrm{ml}$ substrate in optimized medium, which is very close to the actual level of xylanase produced in the optimized medium, which was $27.77 \mathrm{UA} / \mathrm{ml}$ wheat bran. The xylanase yield in the optimized medium, which was three-fold higher than that in the initial medium (Fig. 7). The dynamics of xylanase production in $\mathrm{SmF}$ using initial and optimized media showed maximum enzyme production after $90 \mathrm{~h}$ of fermentation.

A response surface method with a five-factor, three-level design has been used to optimize the medium components, agitation and incubation period for maximum xylanase production by Streptomyces violaceoruber in $\mathrm{SmF}$, which resulted in a maximum production of $1,500.0 \mathrm{IU} / \mathrm{ml}$ (Khurana et al. 2007). Similarly, xylanase production by Bacillus coagulans BL69 has been maximized by the CCD method, with maximum xylanase yields of $1.47 \mathrm{IU} / \mathrm{mg}$ protein in SSF (Heck et al. 2005).

Little information on the optimization of xylanase production using Streptomyces sp. in $\mathrm{SmF}$ is available in the scientific literature. The aim of this work was to enhance xylanase production by Streptomyces sp. P12-137, which has proved to be a potentially useful strain during previous screening studies, by using CCD based on the optimization of some culture parameters (carbon source, nitrogen source, xylanase inductor production) involved in SmF processes. These factors are important in shortening fermentation periods for potential industrial applications by maintaining appropriate substrate concentration in the medium, which can make the whole process more economical and feasible.

The 3D response surfaces were plotted to work out the interactions among the selected factors, and to determine the optimum concentration for obtaining maximum xylanase production. The coordinates of the central point within the highest contour lines in each of the graphics correspond to the optimum concentration of the respective components.

The xylanase yield increased upon increasing the concentration of wheat bran (above $2.0 \%$ w/v). Khurana et al. (2007) found the same result using Streptomyces violaceoruber under $\mathrm{SmF}$ at $37^{\circ} \mathrm{C}$ for $54 \mathrm{~h}$ under shaking (200 rpm). The wheat bran serves as a nutrient reservoir for xylanolitic microorganisms. In a report by Beg et al. (2000), wheat bran effectively induced higher xylanase production by Streptomyces sp. OG -11-3. Techapun et al. (2002b) obtained the maximum yield of xylanase of about $15 \mathrm{IU}$ at $50^{\circ} \mathrm{C}$ and $\mathrm{pH} 7$, by using cane bagasse - a carbon source from the agricultural waste-and Streptomyces sp. Ab106. Beg et al. (2000) reported a Streptomyces sp. QC 113 strain that produces $7.5 \mathrm{IU}$ xylanase in a wheat bran medium at $37^{\circ} \mathrm{C}$ at $\mathrm{pH} 8.0$ after 5 days. Antanopoulos et al. (2000) reported $12 \mathrm{UI} / \mathrm{ml}$ xylanase in a xylan medium using Streptomyces albus at $30^{\circ} \mathrm{C}$ at $\mathrm{pH} 7.5$ after 5 days.

\section{Conclusion}

This work has demonstrated that CCD and regression analysis methods were effective in determining the optimized carbon source, nitrogen source and inducer for xylanase activity of Streptomyces sp. P12-137. In this experiment, maximal activity was obtained with medium concentrations of $1 \%$, $\mathrm{w} / \mathrm{v}$ wheat bran and $1 \%, \mathrm{w} / \mathrm{v} \mathrm{KNO}_{3}$ and $0.5 \%$, w/v xylose. The model predicted maximal xylanase production of $29.51 \mathrm{UA} / \mathrm{ml} / \mathrm{min}$ at $2 \%$, w/v wheat bran, $1 \%$, w/v $\mathrm{KNO}_{3}$ and $0.10 \%, \mathrm{w} / \mathrm{v}$ xylose. Under optimal conditions, the activity predicted by the model agreed very well with experimental data, confirming its validity, with a three-fold increase in xylanase activity achieved by optimization of the culture medium composition. These results suggest that the cellulase-free xylanase extract from Streptomyces sp. P12137 strain may present interesting properties for industrial application in pulping and bleaching processes.

Acknowledgments The authors acknowledge material and financial assistance for this work from the Bioaliment Platform and Association of Specialists in Food Biotechnology.

Open Access This article is distributed under the terms of the Creative Commons Attribution Noncommercial License which permits any noncommercial use, distribution, and reproduction in any medium, provided the original author(s) and source are credited.

\section{References}

Antanopoulos VT, Hernandez M, Arias ME, Mavrakos E, Ball AS (2000) The use of extracellular enzymes from Streptomyces albus ATCC 3005 for the bleaching of eucalyptus kraft pulp. Appl Microbiol Biotechnol 57:92-97 
Bailey MJ, Biely P, Poutanen K (1992) Interlaboratory testing of methods for assay of xylanase activity. J Biotechnol 3:257-270

Bas D, Boyaci IH (2007) Modeling and optimization I: usability of response surface methodology. J Food Eng 78:836-845

Beg QK, Bharat B, Mukesh K, Hoondal GS (2000) Enhanced production of thermostable xylanase from Streptomyces sp. OG-11-3 and its application in biobleaching of eucalyptus kraft pulp. Enzyme Microb Technol 27:456-466

Buchert J, Tenkanen M, Kantelinen A, Viikari L (1994) Application of xylanses in the pulp and paper industry. Bioresour Technol 50:65-72

Coman G, Cotârlet M, Bahrim G, Stoughaard P (2008) Increasing the eficiency of screening streptomycetes able to produce glucanases by using insoluble chromogenic subtrates. Romanian Biotechnol Lett 6 [Suppl]:20-25

Goulart AJ, Carmona RM (2005) Partial purification and properties of cellulase-free alkaline xylanase produced by Rhizopus stolonifer in solid-state fermentation. Braz Arch Biol Technol 3:327-333

Haaland PD (1990) Experimental design in biotechnology. Elsevier, New York

Hech JX, Flores SH, Hertz PF, Ayub MAZ (2005) Optimization of cellulase-free xylanase activity produced by Bacillus coagulans BL69 in solid state cultivation. Process Biochem 40:107-112

Khurana S, Kapoor M, Gupta S, Kuhad RC (2007) Statistical optimization of alkaline xylanase production from Streptomyces violaceoruber under submerged fermentation using response surface methodology. Indian J Microbiol 47:144-152

Miller GL (1959) Use of dinitrosalicylic acid reagent for determination of reducing sugar. Anal Chem 3:426-428

Ninave S, Kapoor M, Kuhad RC (2008) Purification and characterization of extracellular xylanase from Streptomyces cyaneus SN32. Bioresour Technol 99:1252-1258

Rosado W, Nadathur SG (2003) Identification of carbohydrate degrading bacteria in sub-tropical regions. Rev Biol Trop 4:205-210

Senthilkumar SR, Ashokkumar B, Chandra R, Gunasekoran P (2005) Optimization of medium composition for alkali-stable xylanase production by Aspergillus fischeri Fxn1 in solid-state fermentation using central composite rotary design. Bioresour Technol 96:1380-1386

Techapun C, Charoenrat T, Poosaran N, Watanabe M, Sasaki K (2002a) Thermostable and alkaline-tolerant cellulase-free xylanase produced by thermotolerant Streptomyces sp. Ab 106. J Biosci Bioeng 4:431-433

Techapun C, Charoenrat T, Watanabe M, Sasaki K, Poosaran N (2002b) Optimization of thermostable and alkaline-tolerant cellulase-free xylanase production from agricultural waste by thermotolerant Streptomyces sp. Ab 106 using the central composite experimental design. Biochem Eng J 12:99-105 